This is a post-peer-review, pre-copyedit version of an article published in Advances in Intelligent Systems and Computing. The final authenticated version is available online at: https://

\title{
Smart, Social, Flexible and Fun: Escaping the Flatlands of Virtual Learning Environments.
}

\author{
Mike Brayshaw $^{1}$, Neil A. Gordon ${ }^{2}$, Simon Grey ${ }^{3}$ \\ 1,2,3 Department of Computer Science and Technology, University of Hull, England, HU6 \\ $7 \mathrm{RX}$. \\ \{n.a.gordon, m.brayshaw, s.j.grey)@hull.ac.uk
}

\begin{abstract}
This paper describes the development of intelligent, social, flexible and game-based pedagogic approaches and their applications in Virtual Learning Environment based Education. Applications of computer science technologies and techniques can enable, facilitate and change educational approaches, allowing scalable approaches that can address both individual student needs whilst managing large - sometimes-massive - cohort sizes. The benefits of these information systems include supporting the wide range of contexts met in education, in terms of individual needs and specific subject and curriculum requirements. Technologies and approaches that are considered range from the representation of knowledge and the use of intelligent systems, the use of social computing, through to the enabling opportunities of ubicomp and the practical application of game mechanics (gamification). This paper concludes with practical illustrations in the context of undergraduate computer science didactics.
\end{abstract}

Keywords: Computer Science Education, Computer Aided Instruction, Pervasive Computing, Flexible Pedagogy, Technology Enhanced Learning, Gamification Based Learning.

\section{Introduction}

Computer Science provides the underpinning and inspiration for a number of educational technologies and techniques. This paper considers a number of computer science based approaches to teaching and learning that are emerging - reflecting the capacity and potential of new technologies and systems. Alongside the systems themselves, this paper also considers the potential benefits of these systems, in terms of pedagogic change, and how this may be applied in practice. In this context, learners, teachers and technologists all represent different forms of user. This paper considers the rise of smart technologies and their impact on pedagogic practice, the different approaches to learning and assessment that they afford, and then goes on to 
consider the impact of social media within this learning mix. It goes on to explore the personalisation and gamification that can be enabled through technology, and in section 6 applies these to the teaching of programming and computer science concepts.

The main context considered in this paper is higher (tertiary) education provided through universities, but the technologies, principles and issues are applicable to the broad range of education provision, from primary through to college, and on to lifelong (work placed and informal) learning scenarios.

The paper provides a discussion of the emerging approaches and systems that provide for technology-enhanced learning, where computer aided instruction is utilized to enable adaptive and flexible solutions for education. The pedagogic approaches are designed to encourage student engagement, whilst enabling the teacher to monitor and manage the student cohort. The paper does focuses in detail on virtual learning environments (VLEs) and Learning Management Systems (LMS). A VLE is a computer based information systems that support learning, teaching and assessment. A LMS is a computer-based system that typically supports learning in a structured way, providing tools to plan and assess the students. Whilst these terms can be used synonymously, a VLE is typically considered as an educational tool, whilst an LMS may support training. In many cases, VLEs consist - or in practice are used - as little more than file management systems; one naïve view is that if they include raw video of recorded lectures this will automatically constitute a positive educational experience. We know that badly authored computer delivered education material does not solve the problem from the legacy of TICCIT and PLATO [1]. In an age where tutorials spring aplenty from the internet and how to videos are offered from all manner of authors and vloggers, it is important and timely to think of the crucial importance of design and content from the point of view of pedagogic delivery and effectiveness for learners. Throwing multimedia at the problem is not the solution. What we propose here is a linked story to provide an effective solution.

An ongoing challenge for computer science education remains the effective teaching of programming - and this provides a fitting context through which to illustrate some of the technologies and techniques described below. In the context of England, this is particularly relevant as the nation embarks on a new computer science curriculum, where computing is developed from primary through to secondary schools, with the challenge of how to roll out programming and related skills and understanding to a majority of the population [3]. This paper provides suggestions about how to apply some of these approaches and ideas to the teaching of programming.

\section{Smart Technologies and Pedagogy}

\subsection{Knowledge Aware Applications}

Semantic Technologies are well-established [4] and can support teaching through the identification of relevant learning materials. A more recent concept - since around 1999 - is that of the Internet of Things (e.g. [5]). Originally proposed as a linkage of devices on their own IP addresses, more recently the Things have been increased in 
range to include Intelligent Software Agencies and Web Services. How we use and interact within these evolving environments is the context for future learning. There is a long history of applying Artificial Intelligence to Computers and Education [5] and [6]. Here we argue not only against the formal behemoth of VLEs but also Intelligent Tutoring Systems. In the world of ubicomp, we expect smart from the devices around us. The domestication of the technology, and how we use it, has led to new models of interaction [7], [8] and [9][9]. The influence of Semantic Technologies is going to see increasing growth of the internet of knowledge aware entities. The world is full of Smart Things. As teachers and learners, we can look to see how interaction with these smart devices is going to change our learning experiences. Knowledge Engineering considerations are thus hidden from users. They typically do not want to know the engineering algorithm behind their GPS or Virtual Assistant. However, from a pedagogical perspective we need to develop knowledge aware applications that are able to deliver this type of functionality to the user.

\subsection{Computer-supported tools for adaptive teaching, learning and assessment.}

When considering traditional classroom - especially university education - one of the key challenges is how to ensure that the material is suitable for individual students. Considering the university context, the efficiency of the lecture format for demonstrating what material is expected is in tension with the actual effectiveness of the lecture format in helping students to understand the material. Such issues are not unique to university, at school level the onus is on teachers to provide individualized learning plans and support. A further issue for teaching contexts is how to manage assessment - the traditional end of material exam can assess learners' knowledge of specific areas, but is limited in terms of identifying learners' actual knowledge of a subject. Computer based systems can provide solutions to some of these issues. The first solution considered is how to provide the learner with appropriate material.

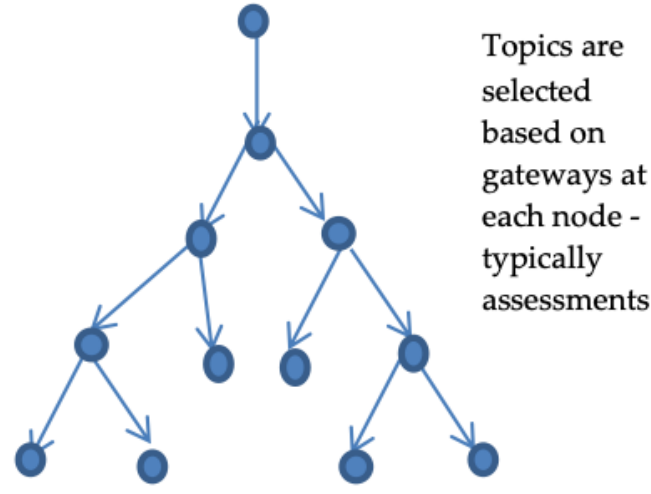


Fig. 1 Directed graph representing hierarchy of topics, concepts and skills - for modelling within the learning system to enable adaptive testing and personalized content.

Computer Science offers a number of technologies and frameworks that can address the issues above, in particular utilizing information markup and intelligent systems to enable personalized learning. As outlined in [10], an approach can be based around computer based diagnostic assessment to identify the learner's current knowledge base, followed up with the direction to the relevant material (level and content). The computer based diagnostic assessment can be made more efficient and effective through an adaptive test - something that traditional education approaches cannot provide. Here, the topics and skills are structured into a tree (See Figure 1), with the root node question being on an initial filtering topic [11]. Further nodes branch depending on the learner's answers, providing an adaptive approach to determine a profile of the learner to be developed. The outcome of this can be an individual learning plan of resources. Further control is provided by identifying suitable gates (tests) that limit access to material until the learner can demonstrate suitable knowledge and skills. Computer systems can automate and control this approach [12], thus providing an adaptive teaching and learning experience. Alongside the diagnostic testing already mentioned, these adaptive systems can personalize the learning experience. In considering educational systems, the role of assessment becomes key.

Historically, computer based assessment has tended to be based around variants of multiple-choice questions [13]. Disciplines with established formal/technical languages - for example, mathematics, computer science and related disciplines have the scope for symbolic evaluation, as illustrated with assessment engines built on evaluating symbolic/mathematical statements and comparing for equivalence - either algebraically or via their outputs. As natural language parsing is improving, and as large learning environments - that we consider later - are developed, another emerging trend will be on systems that can assess narrative text. Some of the current Massive Open Online Courses (MOOC) platforms already offer elements of this. Combining computer assessment with peer assessment, and moderating that with samples of teacher based assessment has the potential to alter how students are assessed.

MOOCS are a good example of such large-scale educational systems. Whilst MOOCS can support the automation of much of the teaching process, the major benefit to organizations utilizing MOOCS - alongside potential marketing and profile raising - is the potential to collate extremely large datasets on learner behavior. Linking back to the earlier discussions on personalized and adaptive systems, the difficulty in creating and managing learning content can be in identifying and maintaining suitable hierarchies of content. MOOCS - and other variants of massive learning systems - may enable machine learning to be applied here, removing the need for direct management by teachers. Such approaches are made more viable as educational web content includes more effective information on their content and use - an application of semantic web technologies [14]. 


\subsection{Machine Learning for Education and Learning Analytics}

As we live online with leave an increasing data trail. Machine Learning provides a way of looking at the history and search for patterns and hidden knowledge. From an educational perspective, what is typically of issue is predication and classification factors of such things as performance and drop out. Educational data mining is a more specialized version of the established data mining in computer science. The nature of educational environments - typically with a variety of data sources and different types of tracking, means they can be grouped under big data. Learning analytics is one aspect of this - where data about student activity (attendance, performance, access to resources, interactions with teachers, tutors and peers) can all be combined to try to profile and support students. Unlike the personalized approaches considered earlier, the onus here is on identifying students who may need intervention of one form or another. The intervention may be for those who appear to be at risk of dropping out or doing badly or it may be to look at how to challenge and develop those who are doing well. Typical educational data mining insights include

- discovering unknown associations;

- finding unknown/hidden rules;

- finding new trends and groups;

- finding new analogical cases to guide insight;

- finding new ways of solving a problem;

- finding new ways of classifying data and predication behavior via neural networks.

If such techniques can identify students that might be in a critical zone then appropriate support, counseling, and remedial material can be made available. How can this be used to implement flexible learning? If we better understand students and are able to label and classify them and more effectively predict their outcomes, then we can improve on the flexibility of the provision provided. By knowing more about their personal performance we can customize provision in both delivery and content. An important distinction to make is in what we are data mining for. In the traditional picture, we are looking at features like marks and attendance or other longstanding benchmarks. What we are arguing for here is that other features of performance are of equal interest. Can we use data mining to find social engagement (other than just attendance)? What can we gain from social media patterns? What can we gain from game engagement patterns and what are the repercussions in terms of educational game engagement? How are they interacting with the smart and what can we mine from that? 


\section{Mixing Social into the Blend}

\subsection{Ubicomp and Social Computing}

The rise of social computing means that there are now generations of users that expect to communication and socialize via computer-mediated communication. This is now a platform that we can look to exploit, delivering interactive educational media. People now instinctively look to the like of YouTube for a video of how to do something new. The rigid likes of a VLE or LMS is no longer the chosen channel of media choice. GitHub embraces both the social and the technical modes of interaction. When people now look to YouTube for a "how to" video they do not want the rigid format of a VLE or a LMS. Indeed if they are forced into such systems, they may typically quit as soon as they get what learning out of it that they originally sought. Github is a good example that embraces both this loose structure of help with a strong social/game (in terms of feedback) element.

\section{Flexible Technologies and Pedagogy}

\subsection{Pervasive and mobile learning systems - overview}

The context of computers and education has changed markedly since the early days of computer based tutoring systems (e.g. [1]. Today computing technology is Pervasive and ubiquitous [8], that it to say it is located in the Smart Telephones, Smart Watches and Smart TVs, and all around our houses; this has changed how we talk and communicate [15]. Today many people carry or wear a computer and access much of their media through these devices. Laptops and Pads add to this rich picture. Thus from an educational context the era of mobile learning is within our technical grasp. How we precisely utilize this from the point of pedagogy is however another issue. Just having the delivery option is not necessarily the whole solution. Distance learning has known problems with isolation, loneliness, and self-motivation (e.g. [16]). The other problem with pervasive is a potential loss of privacy; raising questions such as who can see your mistakes and does this put potential users off?

Pervasive technologies brings with it additional possibilities brought about by games consoles and head mounted displays, which have found their way into the home via entertainment and gaming. Augmented reality [17] is one of these. Through a camera or a helmet, the user sees the world but with an overlying story placed upon it. It has the advantage of being able to use the existing world to contextualize the new information. From the point of view of the learner there are exciting possibilities to locate educational materials. Immersive environments like these allow employment of a real world scenario so that the player can learn as they go along either refining intellectual skills or developing physical skills. Indeed they can do both at the same time. 
Another form of Mobile Learning is to use Cloud based systems. This is already done in some commercial Content Management Systems/Learning Environments (e.g. [18]). The Cloud ensures that the material is available anywhere and on anything that has a connection, thereby increasing the pervasiveness of the interaction.

\subsection{The transformational impact of Social media in teaching and learning}

Through social media, we are able to construct a world around us, a lens by which we can shape our own unique view of the world. It is a world where one-to-one and oneto-many is possible. The pervasiveness of communication technology and every day of synchronous and asynchronous communication is one of the great changing events of our time. Email, Twitter, YouTube and Facebook are ubiquitous communication tools that form a part of everyday life. The empower users both as authors and audience for this new media traffic. They thus have the potential to transform how we deliver material to users. They also have the potential to change completely the two-way interaction in that how students interact with the teachers is changed. Students may be asked to make and share their work using a wide range of media forms. Traditional problems like loneliness and isolation that distance educators often report may be change by this new social media experience.

That said there are down sides as well. Bullying and Trolls are a frequent story in the news. We must be aware that the use of social media is not necessarily all good news. How to use social media in a positive way is a big research question for designers of educational material.

\subsection{Remote and virtual classrooms and laboratories?}

In this new world, are classrooms and laboratories dead? In [16] the whole of the Summer School was scaffolded around the notions of a tradition University Campus and the affordances that that can bring. Library materials for example where it the Library. Virtual Laboratories provide the potential for learning and collaborating just as before. However, they can now be seen here in the context of pervasive computing, augmented reality and social media. Rather than being old notions, they are now rich lands in which traditional models, but now with the constraint to physically collocated and enhance by anytime, anywhere possibilities and the social world potentially of the users' choice.

\subsection{Flexible Learning and Personalization}

Flexible learning [19] is concerned with the three dimensions of learner choice [20], namely the where, when and how to learn. This pedagogic viewpoint reflects the wide variety of learners across Higher Education, where assumptions that students are based in classroom or campus scenarios, with their study as their major focus are questioned. Whilst distance learning and personalized material suitable for individual 
learning style are not new concepts - they are difficult and impractical in large-scale teaching. What Computer Science can facilitate is the upscaling of such provision with mobile devices allowing for choice in place, computer based teaching allowing for choice in when, and at what pace, to learn, and computer mediated learning providing flexibility in how to learn.

As with any information system solution, learning technologies do not provide an ideal answer -in mapping them on to the teaching and learning process, the typical issues of ensuring that the systems meet the range of users requirements and needs arises - something considered later in this paper.

With the adaptive systems mentioned in the previous section, this allows for the modelling of learning as a directed graph, with multiple paths depending on the choices, preference and performance of the learner. The role of the teacher with this approach moves from a focus on providing content, to a broader role where the main aim is to support the learner in managing their learning.

There is no need to include page numbers. If your paper title is too long to serve as a running head, it will be shortened. Your suggestion as to how to shorten it would be most welcome.

\subsection{Authoring and management of learning content}

The World Wide Web and related technologies have been disruptive in allowing access to new resources and raised new issues around plagiarism, assessed work by contract, and social and peer support can veer from collaboration to collusion. The ready access to material raises the problem of intellectual property and fair use - an issue for learners and teachers alike. Reusable learning objects - followed by the notion of customizable ones - give the potential for sharing teaching materials. Approaches such as the Learning Object Metadata (LOM) [20] and Learning Materials Application Profile [21] provide a specification for the description and vocabulary for learning objects. However, but technical standards have yet to catch the attention of the majority of practitioners.

Taking inspiration from the software engineering component approach to software, a component based approach to educational material seems opportune - where interfaces are defined semantically, allowing the intelligent systems described earlier to assemble learning resources and landscapes, for the learners to traverse with their teacher guides.

The management and ownership of learning content becomes more complex with the move towards cloud based virtual learning environments, and to sharing resources. Copyright and more general Intellectual Property Right issues (IPR) issues that may be hidden within institution based lessons, are exposed where material is shared through internet sites, whether as part of an online course such as a MOOC, or part of blended learning supporting more traditional campus-based education. 


\section{Having Fun! Gaming Technologies and Pedagogy}

\subsection{Game-based learning, gamification and edutainment}

For a long time play has been recognized as an important part of learning. In a study of the role of play in human culture Huizinga identifies that play has an important role in development, noting that the word 'school' has a foundation in play "Meaning originally 'leisure' it has now acquired precisely the opposite sense of systematic work and training" [22]. Celebrated game designer Chris Crawford claims that "the fundamental motivation for all game playing is to learn" [23] while Koster makes the bold claim that "Fun is just another word for learning" and those games are ultimately teachers [24]. As learners grow older it seems that the role of play is discarded in favor of more serious educational pursuits, and that this transition is accompanied by reduced engagement with learning, whilst games continue to be enjoyed by a wide variety of people. Game-based learning, gamification and serious games all attempt to use aspects of games to increase engagement with teaching subject matter.

In the case of game-based learning, subject matter is embedded within a game. A game is created with the aim of teaching concepts through playing the game. Unfortunately, the commercial genre of games label "edutainment" seems to be more associated with poorly designed, poorly executed games [25]. It is proposed that this is largely due to a combination of poor game design, poor understanding of learning $\&$ teaching, and lack of funding in comparison to mainstream games. People of a certain age may fondly remember the highly successful edutainment title "Where in the world is Carmen Sandiego", but that title was released in 1983 when gaming was still in its infancy and budgets were small.

By contrast, "serious games" are most often used by organizations with access to large amounts of funding, such as the military [19]. Serious games tend to use technology originally developed for use in games to provide serious training opportunities in immersive simulated environments, often with a trainer observing and adapting the environment to create specific scenarios and learning experiences. The field of serious games represents a clear-cut example of technology-enhanced learning, and in particular, learning enhanced specifically by technology developed primarily for use in games. Consumers of serious games often have access to significantly larger budgets and

Gamification has risen in popularity over the past five years. The Gartner group first plotted gamification climbing the peak of inflated expectations on its hype cycle for emerging technologies in 2011 [26]. By 2014, gamification has surpassed the peak and is currently slipping into the trough of disillusionment [27]. In both cases, gamification was expected to reach maturity in five to ten years. Zichermann and Cunningham define gamification as "The process of game-thinking and game mechanics to engage users and solve problems" [28] whilst Kapp combines elements of a variety of definitions to arrive at the definition "Gamification is using gamebased mechanics, aesthetics and game thinking to engage people, motivate action, promote learning, and solve problems." [29]. Werbach and Hunter offer the more general, simplified definition of "The use of game elements and game design 
techniques in non-game contexts" [30] and often forms a layer of extrinsic motivators striving to complement the learning experience.

Gamification often borrows established concepts from games including feedback mechanisms (such as points and badges), element of competition (leaderboards), decreased risk (multiple lives), adaptive challenges (difficulty levels) and meaningful choice (customization) has game elements layered on top of the subject matter.

Specifically in the field of learning and teaching Dicheva et al present a review of papers reporting the application of game elements to education. 34 papers were analyzed, all of which were published between 2010 and 2014 inclusively [31]. By categorizing the content of these papers Dicheva also confirmed that "the most popular game mechanics are points, badges and leaderboards", which has become such a synonymous phrase for gamification that this trio of game elements is often shortened to the acronym PBL (Points, Badges and Leaderboards). Whitton presents a wider account of the role of digital games and learning by considering games from a series of both complimentary and contrasting perspectives [32].

As gamification has risen in popularity, work has been done to make gamification more accessible. One example of this is the Mozilla Open Badges initiative [33], which offers user a method to earn badges from multiple issuers, store them in a single combined "Mozilla Backpack" and display them across a variety of social networks. Similarly, Dicheva et al present a prototype gamification framework for skills based learning to enable such courses to be gamified [34]

As gamification becomes more popular, and more accessible as a tool for teachers to utilize as they try to engage their students, it is worth remembering that designing effective gamified experiences is not an easy task. Werbach and Hunter caution that designers of gamified experiences should not "mindlessly attach extrinsic motivators to activities that can be motivated using intrinsic regulators." [30].

It is proposed that gamification is best considered as an easy to understand metaphor for a group of well-established techniques routed in psychology. In particularly, Deci and Ryan's self-determination theory of motivation [35] highlights the need for an appropriate level of challenge (mastery), meaningful choices (autonomy) and a (purpose). Csziksentmilayhi's concepts of flow [36] again demonstrates that challenges are most engaging when they are at a level appropriate to an individual's skill (customization). Finally, Dwecks theories on motivation applied to learning [37] promote a mindset that accepts failures as opportunities to learn, and highlights the need for activities that are low risk and provide fun failure.

Similar themes arise in the field of games design. Games designers try to engage their players in the same way as teachers try to engage their students. Schell proposes that a game can be considered a designed experience [38][38]. It is proposed that learning and teaching is different only in that designed learning experiences have an ultimate goal of achieving a specific learning outcome. Whilst being mindful of that difference it is proposed that some games design methodologies can be extended to any designed experience.

In particular, the Mechanics-Dynamics-Aesthetics model for game design [39] recognizes the different approaches taken by game designer, building a game's mechanics, and the game player, partaking in the game's aesthetic experience. Mechanics are the rules of the game as created by the game designer. Dynamics are behaviors, both expected and unexpected, that arise because of those rules. Aesthetics 
are the experiences of individual players. The same concept can be applied to anyone designing any experience for another person. In the case of learning and teaching, the teacher is responsible for the mechanics. They create teaching material to interact with, rules to adhere to, such as compulsory monitored learning activities and goals to strive towards, such as assessment. The dynamics that define the learning experience (aesthetics) might be that students focus mostly on activities that they perceive will move them closer to the assessment, or activities that will avoid incurring a penalty such as attending monitored activities. Similarly, when creating a gamified activity it is important to consider the underlying motivations of learners, and the likely effect of any additional extrinsic motivation may have on the overall learning experience.

\section{Flexible Approaches to Introductory Programming, Algorithms, and Computer Science}

We have here argued for the notions of smart, social, flexible and fun to be key motivation devices in design of future education delivery. In line with the above work we have applied these ideas in the following Computer Science Undergraduate contexts

- A Flexible Approach to Teach Introductory Programming

Providing options of pace and place, programming learning is supported with miniworkshop activities (akin to mini-lectures) to break the concepts down into manageable elements for students. By scaffolding their programming within a constrained environment, they focus on the specific programming construct rather than being overwhelmed or confused by needing to fit within a full programming IDE. However, the focus is on text-based programming, rather than the block based graphical approach, which can make the programming learning less effective.

- Enquiry Based Learning for Exploring Computer Science

Enquiry based learning lets the learner be the driver of their learning experience and follow their own user-derived path. Thus the flexibility is in the users own volition and task agenda.

- Guided Discovery Tutoring of Introductory Programming

Building on discovery learning (the idea the to construct new ideas users are best served by discovering new knowledge in terms of their already existing mental models [40] and [41]) the approach here was after [42] in terms of guiding users to their discovery in the context of first year computer programming.

- Gamification of Programming Exercises

Going beyond the normal quizzes, we have sought to make these games in their own right so that the underlying story is a game with programming just being the location. The idea of the interaction is fun, with programming providing a location for that fun. 
- The use of social interaction techniques and discussions as a location and forum talking about programming and algorithmic issues as illustrated in Figure 2..

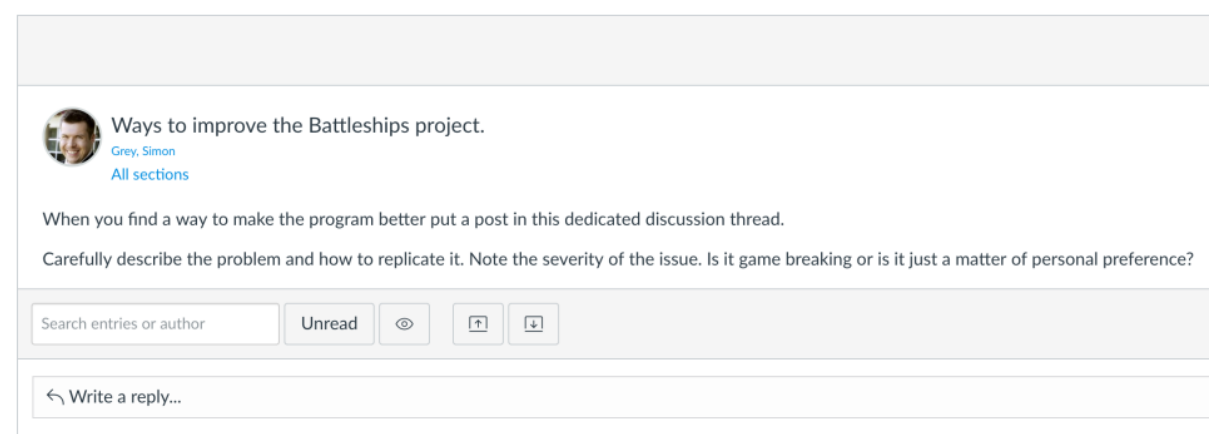

Fig. 2 An example of a social media discussion on the topic of algorithms. Here discussing ways to improve a game algorithm.

- Flexible and highly interactive methods to socially engage and provide fun for students

Whilst lectures are sometimes decried for their lack of engagement, modern technology such as in-class voting and interaction - means that students can provide feedback and actively participate in a lecture-based activity. This can range from voting on an answer, to free text (though the latter can lead to inappropriate content, so needs judicious use). This technology can enable students to see the process of research - both in gathering data, as well as the pit-falls of leading questions.

- Knowledge Aware Apps for personalising services - based upon existing profiles smart knowledge ware technologies personalise the delivery of services. This can include the combination of separate needs knitted together into a single services

These therefore are starting locations for the work outlined here that we aim to move forward with in the future.

\section{Conclusions}

Computing's influence on educational has been significant to date, but the next generation of systems - with ubicomp providing anytime, anyplace with intelligent systems providing bespoke material tailored to the individual learner's needs - offers a step change in how people learn. The move towards cloud based learning environments, and support for augmented reality - will further soften the distinction between formal and informal learning. For traditional education providers, the challenge is in ensuring that the blend of online and ubicomp learning complements and enhances other learning. For many new learners, such blends of traditional and 
computer mediated learning will not be relevant, and intelligent pervasive educational systems will be providing for the lifelong learning that is so difficult in many economies and contexts.

Flat content management systems for education do not reflect what learners require and expect. They are frequently very rigid with a one size fits all mentality. The education designer is frustrated having to fit the goals of their learning outcomes into the limited tools available (e.g., multiple choice quizzes). They do not compete against the rest of the dynamic and fun elements of today's online world. If we are to generate new learning management systems, they must reflect what is around. This is not only just in terms of content, but also of interactive experience. When people go online today their experience is varied and to their own calling. In other words, it is highly flexible. We live in world where smart is all around. We live social lives online. We like having fun. The challenge for computer science is to ensure that that the next generation educational technologies are truly enhancing learning, reflect the above concerns, and so developing better ways to capture the requirements and to deliver future neophytes.

\section{References}

[1] Self, J., and O'Shea, T.M., Learning and Teaching with Computers, Harvester Press, 1983.

[2] Pinner, R., 2014, What Is The Difference Between an LMS and a VLE?, https://elearningindustry.com/difference-between-lms-and-vle, Last Accessed 2019/02/2014.

[3] Departement for Education, 2018, Schools Minister announces boost to computer science teaching, https://www.gov.uk/government/news/schools-minister-announces-boost-to-computerscience-teaching, Last Accessed 2019/02/14.

[4] Berners-Lee, T., Hendler, T., and Lassila, O., The Semantic Web: A new form of Web content that is meaningful to computers will unleash a revolution of new possibilities, Scientific America, https://www-

sop.inria.fr/acacia/cours/essi2006/Scientific\%20American_\%20Feature\%20Article_\%20The\%20 Semantic\%20Web_\%20May\%202001.pdf, (2001), last accessed 2018/10/12.

[5] Höller, J., Tsiatsis, V., Mulligan, C., Karnouskos, S., Avesand, S., and Boyle, D., From Machineto-Machine to the Internet of Things: Introduction to a New Age of Intelligence, Elsevier, (2014).

[6] Sleeman. D., and Brown, J.S., Intelligent Tutoring Systems, Academic Press, London, (1982 ).

[7] Madianou, M. and Miller, D., 2012. Polymedia: towards a new theory of digital media in interpersonal communication. International Journal of Cultural Studies, 15(1), (2012).

[8] Madianou, M. and Miller, D., Migration and New Media: Transnational Families and Polymedia. London: Routledge. 2011

[9] Karatzogianni, A. 2015. Firebrand Waves of Digital Activism 1994-2014: The Rise and Spread of Hacktivism and Cyberconflict, Basingstoke: Palgrave MacMillan.

[10] Gordon, N., Enabling Personalised Learning through Formative and Summative Assessment, in Technology-supported Environments for Personalized Learning: Methods and Case Studies, Edited by J.O'Donoghue, P.A.Hershey, Information Science Publishing. (2009).

[11] Appleby, J., Samuels, P., and Treasure-Jones, T., Diagnosys - a knowledge-based diagnostic test of basic mathematical skills, Computers \& Education vol. 28, no. 2, pp. 113-131, (1997).

[12] Wen, L. , Brayshaw, M., and Gordon, N., Personalized content provision for virtual learning environments via the semantic web, Innovation in Teaching and Learning in Information and Computer Sciences, vol. 11, no 1, pp 14-26 (2012).

[13] Thelwall, M., Computer-based assessment: a versatile educational tool, Computers \& Education, vol. 34, 
no. 1, pp. 37-49, (2000).

[14] Brayshaw, M., and Gordon, N., Managing learning resources-technical issues with learning objects, repositories and searching the semantic web, Proceedings of the 2009 eTeaching and Learning Workshop, pp. 28-32, (2009).

[15] "IEEE Pervasive Computing”, http://www.computer.org/csdl/mags/pc/2015/01/index.html , (2015) last accessed 2018/10/12.

[16] Eisenstadt, M., Brayshaw, M., Hasemer, T., and Issroff, K., Teaching, Learning and Collaborating at an Open University Virtual Summer School, in A. Dix and R. Beale (Eds.) Remote Cooperation: CSCW Issues for Mobile and Teleworkers. London: Springer, (1996).

[17] Shumaker, R., and Lackey, S., (Eds), "Virtual, Augmented and Mixed Reality (Part 1 \& 2)", LNCS 8525 \& 8526, Springer, (2014).

[18] Desire2Learn, http://www.d21.com/ (2015), last accessed 2018/10/12.

[19] Higher Education Academy, "Flexible Learning" http://www.heacademy.ac.uk/flexible-learning, (2013), last accessed 2018/10/12.

[20] Zope, The UK LOM Core home page. http://zope.cetis.ac.uk/profiles/uklomcore, (2008), last accessed 2018/10/12.

[21] LMAP Learning Materials Application Profile Scoping Study. http://www.icbl.hw.ac.uk/lmap/, (2008), last accessed 2018/10/12.

[22] Huizinga, J., Homo Ludens: A Study of the Play-elememt in Culture. Beacon Press, p148, (1955)

[23] Crawford, C., The art of computer game design, (2010).

[24] Koster, R., Theory of fun for game design, O'Reilly Media, Inc., (2013).

[25] Goldstein, K., Why Did Edutainment Become a Bad Word?, Computers in Entertainment. (2014).

[26] Fenn, J., and Hung, L., Hype cycle for emerging technologies: 2011, Gartner, 2011.

[27] Gartner, "Hype Cycle for Emerging Technologies", 2018, https://www.gartner.com/doc/3885468/hypecycle-emerging-technologies- , last accessed 2018/10/12.

[28] Zichermann, C., and Cunningham, C.,., "Gamification by design: Implementing game mechanics in web and mobile apps.", O'Reilly Media, Inc., p. xiv, 2011.

[29] Kapp, K., "The gamification of learning and instruction: game-based methods and strategies for training and education", John Wiley \& Sons, p 17, 2012

[30] Werbach, K., and Hunter, D., "For the win: How game thinking can revolutionize your business", Wharton Digital Press, p26, 2012.

[31] Dicheva D., Dichev, C., Agre, G, and Angelova, G., "Gamification in Education: A Systematic Mapping Study", Educational; Technology and Society(2015).

[32] Whitton, N., "Digital Games and Learning: Research and Theory", Taylor \& Francis, 2014.

[33] Open Badges, http://openbadges.org/, 2014.

[34] Dicheva, D., Irwin, K, Dichev, C., and Talasila, S., "A course gamification platform supporting student motivation and engagement", Web and Open Access to Learning (ICWOAL), 2014 International Conference, 2014.

[35] Deci, E. L. and Ryan. R. M. "Self-determination theory", Handbook of theories of social psychology vol. 1 pp. $416-433,2011$.

[36] Csikszentmihalyi, M., "Flow", Springer Netherlands, 2014.

[37] American Psychologist, Special issue: Psychological Science and Education, vol. 41, no. 10, Oct,. pp. 1040-1048, 1986.

[38] Schell, J., "The Art of Game Design: A book of lenses", CRC Press, 2014.

[39] R. Hunicke, M. LeBlanc, and R. Zubek. "MDA: A formal approach to game design and game research", Proceedings of the AAAI Workshop on Challenges in Game AI. vol. 4. 2004

[40] Bruner, J. S., 1961, "The act of discovery". Harvard Educational Review 31(1): 21-3

[41] Papert S, 1980, Mindstorms: Children, Computers and Powerful Ideas, Brighton: Harvester Press.

[42] Elsom-Cook, M, 1990a, Guided Discovery Tutoring in M Elsom-Cook (Ed) Guided Discovery Tutoring: A Framework for ICAI Research, London: Paul Chapman, ISBN 0442308353 